\title{
Valores Referenciais para Procedimentos Odontológicos (VRPO) em Ortodontia
}

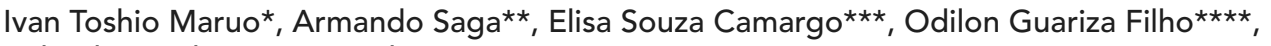

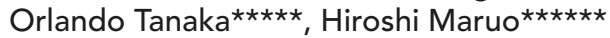

\section{Resumo}

Introdução: a discussão sobre o valor dos honorários a serem cobrados pelo tratamento ortodôntico é importante e bastante atual. Objetivo: o objetivo da presente pesquisa foi analisar os fundamentos dos atuais Valores Referenciais para Procedimentos Odontológicos (VRPO) nos procedimentos ortodônticos. Métodos: para analisar esse tema do ponto de vista legal, ético e científico, foram utilizados documentos legais, matérias de entidades de classe odontológica e artigos científicos. Resultados: a legislação é genérica e apenas fornece parâmetros abstratos para definir o valor dos honorários. Os VRPO atuais variam dentro do mesmo Estado, conforme a entidade que se consulte. As entidades odontológicas interpretam que os procedimentos ortodônticos corretivos podem ser praticados por qualquer cirurgião-dentista clínico geral, mas já surgem trabalhos científicos na literatura que afirmam o contrário. A Associação Brasileira de Ortodontia e Ortopedia Facial (ABOR) propõe que sejam formulados VRPO específicos para a Ortodontia. Conclusão: os VRPO atuais não são padronizados e estão abaixo do valor correto para os procedimentos ortodônticos corretivos, pois são as médias dos valores cobrados por cirurgiões-dentistas especialistas e por clínicos gerais; e a ABOR está embasada legal e eticamente para exigir VRPO específicos para a especialidade da Ortodontia.

Palavras-chave: VRPO. Convênios odontológicos. Honorários.

\section{INTRODUÇÃO}

A discussão sobre o valor dos honorários a serem cobrados pelo tratamento ortodôntico é sempre atual. Duas notícias a esse respeito - veiculadas recentemente, em 2008 - mereceram ampla discussão pela classe odontológica, mais particularmente pelos ortodontistas.

A primeira delas foi uma reportagem exibida pelo Jornal Nacional, em 25 de janeiro de 2008, sobre o Congresso Internacional de Odontologia de São Paulo ${ }^{7}$. Nessa matéria, um profissional fez a polêmica afirmação que se, antigamente, o tratamento ortodôntico era caro, hoje ele custa $\mathrm{R} \$ 60,00$ por mês. Tal fato gerou descontentamento em vários ortodontistas, pois esse foi considerado um valor irrisório.

* Mestre e doutorando em Ortodontia (PUCPR). Bacharel em Direito, Faculdade de Direito de Curitiba, Faculdades Integradas Curitiba (FIC).

** Mestre e doutorando em Ortodontia (PUCPR). Professor do curso de especialização em Ortodontia/ABO-PR.

*** Mestre e doutora em Ortodontia (UFRJ). Professora adjunta (graduação e pós-graduação em Odontologia - Ortodontia / PUCPR).

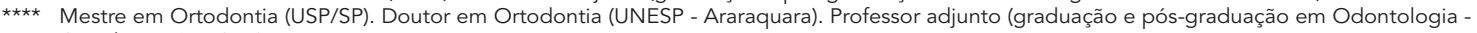
Ortodontia / PUCPR).

***** Mestre e doutor em Ortodontia (UFRJ). Diplomado pelo Board Brasileiro de Ortodontia e Ortopedia Facial (BBO). Professor titular (graduação e pós-graduação em Odontologia - Ortodontia / PUCPR).

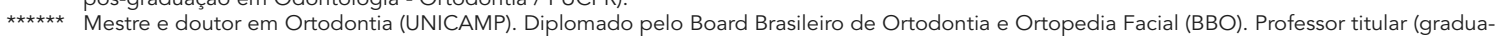
ção e pós-graduação em Odontologia - Ortodontia / PUCPR). 
A segunda notícia, veiculada pelo Conselho Federal de Odontologia (CFO) ${ }^{5}$, foi que as Entidades de Classe Odontológica - CFO, Associação Brasileira de Cirurgiões-Dentistas (ABCD), Associação Brasileira de Odontologia (ABONacional), Federação Interestadual de Odontologia (FIO) e Federação Nacional de Odontologia (FNO) - contrataram a Fundação Instituto de Pesquisas Econômicas de São Paulo (FIPE) para atualizar os Valores Referenciais para Procedimentos Odontológicos (VRPO) e, para tanto, deveria ser seguida uma metodologia científica ${ }^{5}$. Há algum tempo, tem havido um imenso esforço para que os VRPO sejam adotados como preços mínimos a serem pagos pelos convênios.

Os VRPO deveriam ser padronizados, mas isso não ocorre na prática. Por exemplo, os valores encontrados para procedimentos ortodônticos no Paraná são diferentes pelo Conselho Regional de Odontologia do Paraná (CRO/PR) ${ }^{6}$ e pelo Sindicato dos Odontologistas do Paraná (SOEPAR) ${ }^{15}$ (Tab. 1), mesmo que ambas as sociedades façam parte da Comissão Estadual de Convênios e Credenciamentos do Estado do Paraná (CECC/PR).

Neste contexto, o objetivo da presente pesquisa foi analisar os fundamentos dos atuais VRPO nos procedimentos ortodônticos e fornecer base científica para que a Associação Brasileira de Ortodontia e Ortopedia Facial (ABOR), representante dos ortodontistas, possa lutar pelos interesses da classe.

\section{METODOLOGIA}

Para analisar esse tema do ponto de vista legal, ético e científico, foram utilizados documentos legais, matérias de entidades de classe odontológica e artigos científicos.

\section{RESULTADOS E DISCUSSÃO Aspectos legais}

Numa primeira análise, as leis seriam um referencial para a fixação dos honorários a serem cobrados pelo tratamento ortodôntico.
TABELA 1 - VRPO para procedimentos ortodônticos corretivos.

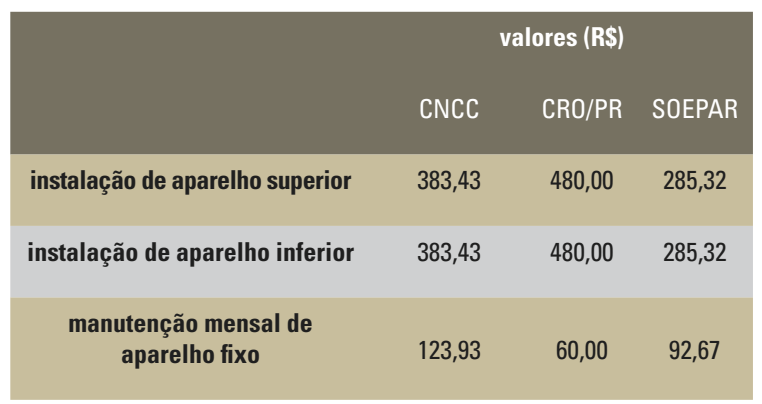

A Constituição Federal ${ }^{3}$, no art. $5^{\circ}$, inciso XIII, garante o livre exercício de qualquer trabalho, ofício ou profissão, atendidas as qualificações profissionais que a lei estabelece.

A esse trabalho, ofício ou profissão deve haver uma contrapartida. O Código Civil² dispõe, em seu art. 594, que toda espécie de serviço ou trabalho lícito, material ou imaterial, pode ser contratada mediante retribuição. Este diploma legal, porém, não fornece parâmetros. A única menção quanto a valores é genérica e está presente no art. 5962: "Não se tendo estipulado, nem chegado a acordo as partes, fixar-se-á por arbitramento a retribuição, segundo o costume do lugar, o tempo de serviço e sua qualidade".

O Código de Ética Odontológica (CEO) $)^{4}$ traz um capítulo sobre honorários com pouca utilidade prática, por também ser muito genérico. Determina o art. 11 do $\mathrm{CEO}^{4}$ que os honorários profissionais necessitam de parâmetros, que são: a condição socioeconômica do paciente e da comunidade; o conceito do profissional; o costume do lugar; a complexidade do caso; o tempo utilizado no atendimento; o caráter de permanência, temporariedade ou eventualidade do trabalho; a circunstância em que tenha sido prestado o tratamento; a cooperação do paciente durante o tratamento; e o custo operacional.

Não havendo disposições legais expressas, cabe ao mercado e à classe odontológica conjuntamente definirem quais são esses parâmetros. 


\section{VRPO}

Desde a década de 80, a Comissão Nacional de Convênios e Credenciamentos (CNCC) - composta pelo $\mathrm{CFO}, \mathrm{ABCD}, \mathrm{ABO}-\mathrm{Nacional}$, FIO e FNO - busca definir valores referenciais para procedimentos odontológicos que protejam os cirurgiõesdentistas do aviltamento profissional na relação com as operadoras de planos de saúde e sejam, ao mesmo tempo, compatíveis com o mercado ${ }^{5}$.

Nesse sentido, foram criados os VRPO, considerando os custos fixos e variáveis de cada procedimento. O reajuste dos VRPO se dá com base no IGPM anual, sempre no mês de julho. Por orientação da CNCC, cada Estado organizou seus VRPO, visando refletir realidades locais ${ }^{8}$.

\section{VRPO e os procedimentos ortodônticos - uma análise crítica}

Os VRPO deveriam ser fontes seguras a respeito do valor de qualquer procedimento odontológico. Porém, isso não ocorre na prática. A CNCC fornece um parâmetro ${ }^{8}$ e determina que cada Comissão Estadual faça a adequação à realidade de seu Estado. Mesmo assim, o CRO/PR ${ }^{6}$ e o SOEPAR ${ }^{15}$, por exemplo, divergem nos valores de cada procedimento (Tab. 1), mesmo que ambas as entidades dirijam a CECC-PR. Como não há hierarquia entre elas, surge a dúvida sobre qual valor deve ser adotado. O cirurgião-dentista que comentou os custos do tratamento ortodôntico na reportagem do Jornal $\mathrm{Nacional}^{7}$ está coerente com o valor do $\mathrm{CRO} / \mathrm{PR}$, mas não do SOEPAR.

Além disso, ao final da tabela dos VRPO, há a observação de que qualquer cirurgião-dentista está apto a realizar estes procedimentos odontológicos, conforme a Lei 5081, que regulamenta a profissão do cirurgião-dentista ${ }^{6,8,15}$. Tal afirmação, porém, é errônea no que diz respeito aos procedimentos ortodônticos, como manutenção e instalação de aparelhos superior e inferior.

Maruo et al. ${ }^{10}$ demonstraram que, segundo as leis e os julgados dos tribunais, no Ordenamento Jurídico brasileiro, ao cirurgião-dentista clínico não-especialista é vedada a prática da Ortodontia Corretiva. Isto porque as Diretrizes Curriculares Nacionais do Curso de Odontologia determinam que, na graduação, somente deve ser realizado o ensino da Ortodontia Preventiva e, por se tratar de procedimento de saúde, somente os cursos de Especialização, Mestrado e Doutorado em Ortodontia possuem fiscalização do Poder Público. Em outro trabalho, Maruo et al. ${ }^{11}$ mostraram que tal política é compativel com a adotada por países como Portugal (do qual o Brasil herdou o sistema jurídico) e Estados Unidos (do qual a Ortodontia brasileira herdou muito de sua política e ciência).

É importante lembrar que, no mercado, existem tanto os profissionais que fizeram cursos regulares (com maior carga horária e maior necessidade de investimento) quanto aqueles que fizeram cursos com duração de 4 a 8 horas $^{14}$ e as "pragas da Ortodontia"13, que são os cursos de Typodont, cursos ministrados em clínicas particulares, utilizando as denominações de Centro, Fundação, Núcleo, etc. ${ }^{13}$. Os profissionais formados por essas "pragas", além do tratamento odontológico, ofertam tratamento ortodôntico sem o preparo científico necessário ${ }^{12}$.

Tendo em vista esta interpretação errônea do $\mathrm{CFO}$, deve-se considerar que os VRPO para procedimentos ortodônticos corretivos atuais são calculados pela média do que é cobrado tanto por especialistas quanto por clínicos gerais. Como o CEO dispõe que os honorários dependem da formação do profissional, isso significa que os VRPO atuais estão abaixo do valor justo para os ortodontistas. A ABOR já constatou essa discrepância entre os VRPO atuais e os justos, e vem trabalhando para que sejam elaboradas planilhas de custo para cada especialidade. Para tanto, nomeou uma comissão com membros de todas as entidades filiadas à $\mathrm{ABOR}^{1}$. Ainda nesse sentido, essa entidade, questionada por uma paciente, esclareceu que a verdadeira média de custo do tratamento ortodôntico é de $\mathrm{R} \$ 10.000,00$, com uma entrada que varia de $R \$ 2.000,00$ a $R \$ 3.500,00$ e o restante do 
valor parcelado em mensalidades ${ }^{9}$.

A presente pesquisa é a fundamentação teórica e legal que mostra que o trabalho desenvolvido pela ABOR é correto e digno de louvor.

\section{CONCLUSÃO}

1) Os VRPO atuais não são padronizados e estão abaixo do valor correto para os procedimentos ortodônticos corretivos, pois são as médias dos valores cobrados por cirurgiões-dentistas especialistas e por clínicos gerais.

2) A ABOR está embasada legal e eticamente para exigir VRPO específicos para a especialidade da Ortodontia.

\title{
Indicative Values for Dental Procedures (IVDP) in Orthodontics
}

\begin{abstract}
Introduction: The cost of orthodontic treatment is a very important issue. The aim of this study was to analyze the current Indicative Values for Dental Procedures (IVDP) for orthodontic procedures. Methods: Laws, dental entities papers and scientific literature were utilized. Results: Laws are too general and only offer abstract parameters when define remunerations. Current IVDP vary in the same State, according to the consultant entity. Dental entities interpret that general clinicians can practice Corrective Orthodontics, but new scientific studies begin to question this understanding. The Brazilian Association of Orthodontics and Dentofacial Orthopedics (ABOR) suggests that IVDP for orthodontic specialty must be formulated. Conclusion: Current IVDP are not standardized and are below the correct values for orthodontic procedures, because they are the mean of general clinicians and orthodontists remunerations; and ABOR is legally and ethically supported to claim specific IVDP for orthodontic specialty.
\end{abstract}

Keywords: IVDP. Health plans. Remuneration.

\section{REFERÊNCIAS}

1. ASSOCIAÇÃO BRASILEIRA DE ORTODONTIA E ORTOPEDIA FACIAL. Quanto vale um tratamento ortodôntico? Gazeta ABOR, Goiânia, ano 86, n. 1, p. 14-15, jan. 2007.

2. BRASIL. Código Civil: Lei 10.406/2002. Diário Oficial da União, Brasília, DF, 10 jan. 2002.

3. BRASIL. Constituição Federal (1988). Diário Oficial da União, Brasília, DF, 5 out. 1988.

4. CONSELHO FEDERAL DE ODONTOLOGIA (Brasil). Código de Ética Odontológica: Resolução 42/2003. Diário Oficial da União, Brasília, DF, 25 maio 2003.

5. CONSELHO FEDERAL DE ODONTOLOGIA (Brasil). Valor do procedimento terá base científica. Jornal do CFO, ano 16, n. 82, jan./fev. 2008. Disponível em: <http://www.cfo.org.br/ jornal/n82/cbhpo.asp>. Acesso em: 30 jun. 2008.

6. CONSELHO REGIONAL DE ODONTOLOGIA DO PARANÁ Valores referenciais para procedimentos odontológicos: Estado do Paraná. CRO/PR. Disponível em: <http://www.cropr.org.br/ portal/servicos/vrpo.php>. Acesso em: 30 jun. 2008.

7. CRIANÇAS mais novas já podem receber aparelhos nos dentes. Rede Globo de Televisão. Jornal Nacional, Rio de Janeiro, 25 jan. 2008. Disponível em: <http://video.globo.com/ Videos/Player/Noticias/O,"GIM781460-7823-CRIANCAS+MAIS +NOVAS+JA+PODEM+RECEBER+APARELHOS+NOS+DENT ES,00.html>. Acesso em: 30 jun. 2008.

8. FEDERAÇÃO INTERESTADUAL DE ODONTOLOGISTAS. Comissão Nacional de Convênios e Credenciamentos. Valores Referenciais para Procedimentos Odontológicos. FIO. Disponivel em: <http://www.fio.org.br/tabela_vrpo2006.pdf> Acesso em: 30 jun. 2008.

9. FREITAS, J. C. A delicada questão dos honorários. Gazeta ABOR, Goiânia, ano 86, n. 1, p. 24, jan. 2007.
10. MARUO, I. T.; COLUCCI, M. G.; MARUO, H.; TANAKA O.; CAMARGO, E. S.; VIEIRA, S. Estudo da legalidade do exercício profissional da Ortodontia por cirurgião-dentista não especialista. Rev. Dental Press Ortodon. Ortop. Facial, Maringá, No prelo.

11. MARUO, I. T.; SAGA, A.; COLUCCI, M. G.; TANAKA, O.; MARUO, H. O exercício profissional da Ortodontia por cirurgião-dentista não-especialista no Direito Comparado. Rev. Dental Press Ortodon. Ortop. Facial, Maringá, No prelo.

12. PETRELLI, E. A síndrome de Burnout e a Ortodontia. J. Bras. Ortodon. Ortop. Facial, Curitiba, v. 8, n. 44, mar./abr. 2003. Editorial.

13. PETRELLI, E. As pragas da Ortodontia. J. Bras. Ortodon. Ortop. Facial, Curitiba, v. 7, n. 41, set./out. 2002. Editorial.

14. PETRELLI, E. Cursos de Ortodontia de curta duração. J. Bras. Ortodon. Ortop. Facial, Curitiba, v. 7, n. 39, maio/jun. 2002. Editorial.

15. SINDICATO DOS ODONTOLOGISTAS DO PARANÁ. Valores Referenciais para Procedimentos Odontológicos - Estado do Paraná. SOEPAR. Disponível em: <http://www.soepar.com.br/ imagens/vrpo_estadopr.xls>. Acesso em: 30 jun. 2008.

Endereço para correspondência

Ivan Toshio Maruo

Rua Pasteur, 95, Bairro Batel

CEP: 80.250-080 - Curitiba / PR

E-mail: ivan_maruo@yahoo.com.br 